\title{
Gestão de recursos hídricos no Rio Grande do Sul, Brasil
}

\author{
André Panziera, Camila Tamiosso, Alexandre Swarowsky
}

https://doi.org/10.4322/mp.978-65-991393-7-6.c3

\begin{abstract}
Resumo
A Lei Federal Brasileira no 9.433 de 1997 e a Lei Estadual do Rio Grande do Sul no 10.350 de 1994 fundamentaram a bacia hidrográfica como unidade básica de gestão dos recursos hídricos. Na bacia hidrográfica, a convergência dos instrumentos da gestão de recursos hídricos é o plano de gestão da bacia. Este norteia e media demandas múltiplas de outorga e enquadramento, prevê obtenção de recursos financeiros para programas e intervenções, e serve de base para priorização dos recursos da cobrança pelo uso da água. Os comitês de gerenciamento de bacia hidrográfica são posicionados como principais atores na totalidade da bacia, aprovadores de seu plano, administradores e articuladores de debates e conflitos. Embora a regulação legal dos recursos hídricos pareça ter os componentes necessários para a plena articulação das águas, no RS, existe uma lacuna entre gestão e execução. Isso porque, no Rio Grande do Sul, após 26 anos da promulgação da Lei 10.350 de 1994, nem 20\% desta foi implantada. Financeiramente, graves têm sido os entraves com os recursos de manutenção nos Comitês de Bacia Hidrográficas. Assim, percebe-se que o desafio futuro é identificar as lacunas deixadas pela legislação e modernizar a lei. Se, por um lado, os órgãos estaduais hoje ainda possuem várias funções executivas (monitoramento de cheias, manutenção de viveiros de espécies nativas, etc.), por outro os comitês são capazes de perceber a realidade de suas bacias, bem como ações necessárias. Parece, sobretudo, ser preciso balancear mais adequadamente tais atividades.
\end{abstract}

Palavras-chave: Comitês de Bacia Hidrográfica, Gerenciamento de Recursos Hídricos, Leis Federais e Estaduais, Plano de Recursos Hídricos.

\section{Introdução}

O primeiro regulamento brasileiro a reconhecer a água como meio de fomento ao desenvolvimento social e econômico, foi o Decreto Federal $n^{\circ} 24.643$ de 1934 que instituiu o Código das Águas. O objetivo inicial era harmonizar o uso das águas para fins de geração de energia elétrica e agricultura. Embora este Decreto tenha representado normas bastante avançadas para a época, o aumento da diversidade de usos dos recursos hídricos, ao longo do tempo, difundiu percepções e evidências de ineficiência da gestão dos mesmos. Diversos foram os conflitos pelos usos múltiplos entre os setores usuários, tanto pela preocupação ambiental, quanto pela escassez da água.

Foi na Lei $n^{\circ} 6.938$ de 31 de agosto de 1981, a Política Nacional de Meio Ambiente (PNMA), que se atribuiu importante noção de compatibilizar o desenvolvimento econômico-social com a preservação da qualidade ambiental. Não obstante, objetivou- 
se criar critérios, padrões e normas para manejo sustentável dos recursos naturais. Nesse sentido, a partir da década de 90 , os recursos hídricos conceberam considerável avanço, com a instituição de marcos legais específicos tanto na esfera federal quanto na estadual [1]. Tais avanços promoveram na Constituição da República do Brasil de 1988, subsídios significativos para a gestão atual dos recursos hídricos no país. Isso porque, instaurou-se um novo sistema de gestão, baseado na condução descentralizada e participativa, no uso múltiplo da água, na bacia hidrográfica como unidade de planejamento e na água dotada de valor econômico [2]. A Carta Magna também estabeleceu como competência da União, instituir o Sistema Nacional de Gerenciamento de Recursos Hídricos (SINGREH) e definir critérios de outorga de direitos de seu uso, assim como permitiu aos Estados e à União elaborar seus próprios sistemas de gestão de recursos hídricos [3].

Atualmente, as águas no Brasil e Estado do Rio Grande do Sul estão regulamentados por legislações específicas. No Brasil, a lei Federal no 9.433 de 1997 instituiu a Política Nacional de Recursos Hídricos (PNRH), ao passo que no Estado do Rio Grande do Sul, a lei Estadual no 10.350 de 1994 criou o Sistema Estadual de Recursos Hídricos (SERH) $[4,5]$. Ambas são destinadas ao gerenciamento dos recursos hídricos, via efetivação dos instrumentos previstos nas legislações citadas [6]. A água passou a ser entendida legalmente como um bem de valor econômico, que implica em locar equitativamente os mananciais disponíveis. No seu artigo $1^{\circ}$, inciso $\mathrm{V}$, fundamentou a bacia hidrográfica como unidade prática da $\mathrm{PNRH}$, seguindo a tendência mundial, mas facultou a aplicação de todos os seus instrumentos na mesma. O Rio Grande do Sul (RS), antecipou-se à PNRH com SERH, cuja política hídrica também reconhece a bacia hidrográfica como unidade de gestão, integrando nesta a articulação dos efeitos do ciclo hidrológico e suas derivações aérea, superficial e subterrânea.

A convergência dos instrumentos constituintes da lei de recursos hídricos nacional e estadual é o plano de bacia hidrográfica $(\mathrm{PBH})$. Frente a $\mathrm{PNRH}$ e o $\mathrm{SERH}$, percebe-se a importância do $\mathrm{PBH}$ em nortear e mediar as demandas múltiplas de outorga, conforme artigo $13^{\circ}$; obter recursos financeiros para programas e intervenções, conforme item III do artigo 19०; e, servir de base para priorização dos recursos da cobrança pelo uso dos recursos hídricos, quanto ao financiamento de estudos, projetos, programas e obras. Ainda, a práxis do $\mathrm{PNRH}$ e $\mathrm{SERH}$, por região hidrográfica, posiciona os Comitês de Bacia Hidrográfica $(\mathrm{CBH})$ como atuante na totalidade da bacia, aprovador do $\mathrm{PBH}$, administrador e articulador de debates e conflitos acerca dos recursos hídricos. Dessa forma, se valoriza peculiaridades e estratégias de desenvolvimento, inclusive contribuindo com diretrizes da gestão municipal $[7,8]$.

Este cenário inovador, concretiza a decisão de enfrentar, com um instrumento moderno, o desafio de equacionar: a) a demanda crescente de água, face ao crescimento urbano, industrial e agrícola; b) os potenciais conflitos ocasionados pelos usos múltiplos das águas; c) o avanço inquietante da degradação ambiental dos corpos hídricos [9]. Modernos princípios foram incorporados a gestão das águas gaúchas, os quais merecem destaque: a adoção da bacia hidrográfica como unidade de gestão; a outorga e a tarifação pelo uso das águas; e a reversão dos recursos arrecadados em benefício da própria bacia [10]. Porém, embora a regulação dos recursos hídricos pareça ter os componentes necessários a plena articulação das águas, no RS, está existindo uma lacuna entre gestão e execução. No Rio Grande do Sul, após 26 anos da criação do SERH nem 20\% do SERH foi implantado. Nesse sentido, esse trabalho visa discutir a atual situação do sistema de recursos hídricos frente aos instrumentos de planejamento, gestão e estratégicos no Estado do RS, identificando e compreendendo os entraves para a gestão hídrica. 


\section{Sistema Nacional de Gerenciamento de Recursos Hídricos (SINGREH)}

O Sistema Nacional de Gerenciamento de Recursos Hídricos (SINGREH) é composto pelo Conselho Nacional de Recursos Hídricos (CNRH); Agência Nacional das Águas (ANA); Conselhos de Recursos Hídricos dos Estados e do Distrito Federal (CERH); Comitê de Bacia Hidrográfica (CBH) e Agências de Água. Trata-se do grupo de órgãos e colegiados que concebe e implementa a Política Nacional de Recursos Hídricos, de forma democrática e participativa. Os objetivos do SINGREH são coordenar a gestão integrada das águas, arbitrar administrativamente os conflitos relacionados aos recursos hídricos, planejar, regular e controlar o uso, bem como a recuperação dos corpos d'água, e promover a cobrança pelo uso da água.

\subsection{Conselho Nacional de Recursos Hídricos (CNRH)}

O CNRH é o órgão superior do SINGREH, formado por Ministérios e Secretarias da Presidência da República com atuação no gerenciamento ou no uso de recursos hídricos, assim como por representantes dos Conselhos Estaduais, dos usuários e da sociedade civil. As principais competências CNRH acerca dos PBH são: I) promover articulação do planejamento de recursos hídricos em esfera nacional, regionais, estaduais e setores usuários; II) deliberar sobre projetos de aproveitamento de recursos hídricos, cujas repercussões extrapolem o âmbito dos Estados em que serão implantados; III) estabelecer diretrizes complementares para implementação da Política Nacional de Recursos Hídricos, aplicação de seus instrumentos e atuação do Sistema Nacional de Gerenciamento de Recursos Hídricos; IV) aprovar propostas de instituição dos Comitês de Bacias Hidrográficas de rios de domínio da União e estabelecer critérios gerais para a elaboração de seus regimentos; V) aprovar e acompanhar a execução do Plano Nacional de Recursos Hídricos e determinar as providências necessárias ao cumprimento de suas metas; VI) aprovar os valores a serem cobrados pelo uso de recursos hídricos de domínio da União sugeridos pelos comitês de bacia hidrográfica; VII) definir, em articulação com os Comitês de Bacia Hidrográfica, as prioridades de aplicação dos recursos; VIII) aprovar o enquadramento dos corpos de água em classes, em consonância com as diretrizes do CONAMA e de acordo com a classificação estabelecida na legislação ambiental; IX) autorizar a criação das Agências de Água [4]

\subsection{Conselhos de Recursos Hídricos dos Estados e do Distrito Federal}

Os CERH setorizam-se por Estados no Brasil, isto é, norte, nordeste, sudeste, sul e centro-oeste. Tratam-se de colegiados que são compostos, na sua maioria, por representantes dos poderes públicos, dos usuários de água e da sociedade civil. Têm atribuições similares ao $\mathrm{CNRH}$, mas em escala estadual. Estas podem ser separadas em três partes: I) deliberar e acompanhar a execução do plano estadual de recursos hídricos; II) promover a articulação das políticas setoriais relacionadas à água; III) arbitrar conflitos pelo uso da água de domínio estadual [11]. Estima-se que, atualmente, aproximadamente 9.800 profissionais - representantes dos segmentos do poder público, setores usuários e sociedade civil - estejam diretamente envolvidos com as atividades dessas instâncias de gestão descentralizada e participativa [12].

\subsection{Comitês de Bacia Hidrográfica (CBH)}

Os Comitês de Bacia Hidrográfica, denominados "Parlamentos das Águas", são órgãos colegiados que constituem um fórum para o debate e tomada de decisões sobre o destino das águas na bacia de sua jurisdição. Dentre as atribuições dos Comitês, no âmbito de sua área de atuação, referentes aos PBH, destacam-se: I) promover o debate das questões relacionadas a recursos hídricos; II) arbitrar, em 
primeira instância administrativa, os conflitos relacionados a água; III) aprovar e acompanhar a execução do Plano de Recursos Hídricos da bacia, assim como sugerir providências necessárias ao cumprimento de suas metas; IV) propor ao respectivo Conselho de Recursos Hídricos os usos de pouca expressão, para efeito de isenção da outorga, e consequentemente, da cobrança; V) sugerir mecanismos de cobrança pelo uso da água e valores a serem cobrados; e VI) aprovar o plano de aplicação dos recursos arrecadados com a cobrança. Os $\mathrm{CBH}$ são constituídos por representantes da União, dos Estados, do Distrito Federal e dos municípios situados em sua área de atuação, dos usuários da água e de entidades civis com área de atuação situada dentro da bacia.

\subsection{Agência de Bacia Hidrográfica}

A PNRH define que a criação da Agência de Bacia Hidrográfica deve estar condicionada a dois requisitos, a saber: a prévia existência do Comitê ou Comitês de Bacia Hidrográfica e a viabilidade financeira assegurada pela cobrança do uso dos recursos hídricos em sua área de atuação. As Agências de Bacia Hidrográfica visam exercer a função de secretaria do respectivo ou respectivos Comitês de Bacia Hidrográfica (quando a agência abranger mais de um comitê). Usualmente denominado "braço técnico" do $\mathrm{CBH}$, tem atuação nos aspectos administrativos e financeiros e às atividades de articulação no âmbito de um modelo de gestão sistêmica e compartilhada dos recursos hídricos [13].

Dentre suas principais competências, na esfera de sua área de atuação, estão[4]:

I. Efetuar, mediante delegação do outorgante, a cobrança pelo uso de recursos hídricos;

II. Analisar e emitir pareceres sobre os projetos e obras a serem financiados com recursos gerados pela cobrança e encaminhá-los à instituição financeira responsável pela administração desses recursos;

III. Acompanhar a administração financeira dos recursos arrecadados com a cobrança em sua área de atuação;

IV. Elaborar o Plano de Recursos Hídricos para apreciação do respectivo $\mathrm{CBH}$;

V. Propor ao respectivo $\mathrm{CBH}$ :

a. O enquadramento dos corpos de água nas classes de uso, para encaminhar ao respectivo Conselho Nacional ou Conselhos Estaduais de Recursos Hídricos, de acordo com o domínio destes;

b. Os valores a serem cobrados pelo uso de recursos hídricos;

c. Plano de aplicação dos recursos arrecadados com a cobrança; e

d. Rateio de custo das obras de uso múltiplo, de interesse comum ou coletivo.

\section{Sistema de Recursos Hídricos do Estado do Rio Grande do Sul}

O Artigo $n^{\circ} 171$ da Constituição Estadual de 1989 instituiu o Sistema Estadual de Recursos Hídricos (SERH). A Lei Estadual 10.350 de 1994 regulamentou este artigo da Constituição. No Rio Grande do Sul (RS), a política de recursos hídricos também reconhece a bacia hidrográfica como unidade de gestão. O Estado antecipouse à $\mathrm{PNRH}$, com a Lei Estadual $\mathrm{n}^{\circ} \mathbf{1 0 . 3 5 0}$ de 30 de dezembro de 1994, regulamentando o artigo $171^{\circ}$ da Constituição do RS [5]. Esta instituiu o Sistema Estadual de Recursos Hídricos (SERH). No parágrafo único de seu artigo 1ํㅡㅇ os recursos hídricos são integrados no ciclo hidrológico, englobando a derivação aérea, superficial e subterrânea, sendo a bacia hidrográfica a unidade básica de articulação.

Cada bacia hidrográfica do Estado é passível de gerenciamento de um comitê, entidade administrativa e deliberativa de gestão descentralizada, integrada envolvendo 
a participação dos setores da sociedade. Em seu Artigo 10 criou-se na Secretaria do Meio Ambiente e Desenvolvimento Sustentável (SEMA), o Departamento de Recursos Hídricos (DRH). No artigo $38^{\circ}$ fixou-se as três regiões hidrográficas do Estado do Rio Grande do Sul. O Decreto $n^{\circ} 53.885$ de 18 janeiro de 2017 [14], oficializou as 25 bacias atuais (Tabela 1).

Tabela 1. Divisão de bacias, respectivos códigos e áreas entre as regiões hidrográficas do Uruguai, Guaíba e Litoral.

\begin{tabular}{|c|c|c|c|c|}
\hline $\begin{array}{c}\text { Região } \\
\text { Hidrográfica }\end{array}$ & $\begin{array}{l}\text { Comitê de Bacia } \\
\text { Hidrográfica }(\mathrm{CBH})\end{array}$ & $\begin{array}{c}\text { Código } \\
\text { da } \\
\text { Bacia }\end{array}$ & $\begin{array}{c}\text { Decreto } \\
\text { Estadual de } \\
\text { Criação }\end{array}$ & $\begin{array}{c}\text { Área da Bacia } \\
\left(\mathrm{km}^{2}\right)\end{array}$ \\
\hline \multirow[t]{12}{*}{ Uruguai } & Apuaê - Inhandava & U010 & $41.490 / 2002$ & $14.510,51$ \\
\hline & Passo Fundo & U020 & $42.961 / 2004$ & $4.847,25$ \\
\hline & $\begin{array}{c}\text { Turvo - Sta. Rosa - St. } \\
\text { Cristo }\end{array}$ & U030 & $41.325 / 2002$ & $10.824,02$ \\
\hline & Piratinim & U040 & $44.270 / 2006$ & $7.647,26$ \\
\hline & lbicuí & U050 & $40.226 / 2000$ & $35.041,38$ \\
\hline & Quaraí & U060 & $45.606 / 2008$ & $6.658,78$ \\
\hline & Santa Maria & U070 & $35.103 / 1994$ & $15.665,92$ \\
\hline & Negro & U080 & $45.531 / 2008$ & $3.005,24$ \\
\hline & ljuí & U090 & $40.916 / 2001$ & $10.704,60$ \\
\hline & Várzea & U100 & $43.488 / 2004$ & $9.508,42$ \\
\hline & Butuí-Camaquã & U110 & $44.401 / 2006$ & $8.025,76$ \\
\hline & Total & - & - & $126.439,14$ \\
\hline \multirow[t]{10}{*}{ Guaíba } & Gravataí & G010 & $33.125 / 1989$ & $2.008,93$ \\
\hline & Sinos & G020 & $32.774 / 1988$ & $3.680,04$ \\
\hline & Caí & G030 & $38.903 / 1998$ & $4.957,74$ \\
\hline & Taquari-Antas & G040 & $38.558 / 1998$ & $26.323,76$ \\
\hline & Alto Jacuí & G050 & $40.822 / 2001$ & $13.037,20$ \\
\hline & Vacacaí - Vacacaí Mirim & G060 & $39.639 / 1999$ & $11.085,77$ \\
\hline & Baixo Jacuí & G070 & $40.225 / 2000$ & $17.370,48$ \\
\hline & Lago Guaíba & G080 & $38.989 / 1998$ & $2.459,91$ \\
\hline & Pardo & G090 & $39.116 / 1998$ & $3.631,24$ \\
\hline & Total & - & - & $84.555,07$ \\
\hline Litoral & Tramandaí & L010 & $39.637 / 1999$ & $2.745,73$ \\
\hline
\end{tabular}




$\begin{array}{cccc}\text { Litoral Médio } & \text { L020 } & 45.460 / 2008 & 6.472,10 \\ \text { Camaquã } & \text { L030 } & 39.638 / 1999 & 21.517,58 \\ \text { Mirim - São Gonçalo } & \text { L040 } & 44.327 / 2006 & 25.666,83 \\ \text { Mampituba } & \text { L050 } & 49.834 / 2012 & 683,76 \\ \text { Total } & - & - & 57.085,98 \\ \text { bacias hidrográficas } & - & - & 268.080,19\end{array}$

Fonte: $[14,15]$.

Os elementos incorporados para a gestão das águas no Estado são a adoção da bacia hidrográfica como unidade de gestão; outorga e cobrança pelo uso das águas; reversão dos recursos arrecadados em benefício da própria bacia. Para prover a descentralização e participação, fez-se uma matriz institucional (Figura 1) com distintos atores sociais: Conselho de Recursos Hídricos $(\mathrm{CRH})$, Departamento de Recursos Hídricos (DRH), Comitês de Gerenciamento de Bacias Hidrográficas (CBH), Agências de Região Hidrográfica $(\mathrm{ARH})$ e Fundação Estadual de Proteção Ambiental Henrique Luis Roessler (FEPAM).

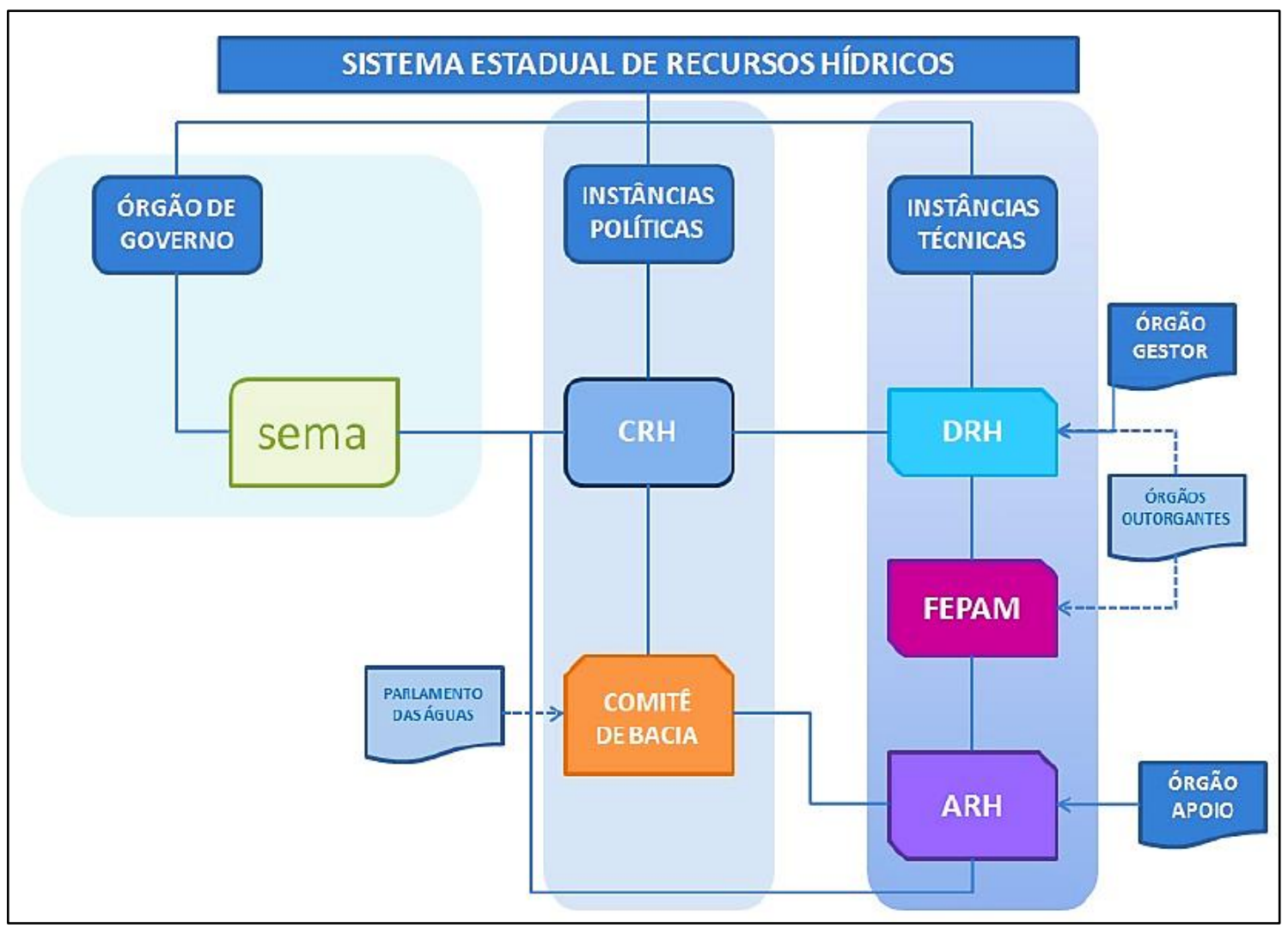

Figura 1. Matriz Institucional do SERH. Fonte: [16].

Verifica-se, na figura acima, que o $\mathrm{CBH}$ é considerado o parlamento das águas, isto é, o ambiente de base de debate e decisão acerca dos recursos hídricos. Os $\mathrm{CBH}$, por isso, têm funções deliberativas, com poderes para decidir sobre aspectos da Política de Recursos Hídricos, administrar conflitos, sendo o $\mathrm{CRH}$ a sua instância superior e, tende este, o dever de legalizar decisões oficializadas no comitê [17], caso não haja 
resolução na instância regional. Na matriz institucional, o $\mathrm{CBH}$, para fins de análise técnica, receberia suporte da primeira instância do órgão de apoio técnico, que é ARH. Mas, atualmente inexiste no Estado a ARH. O SERH/RS destaca a composição dos comitês sob sua jurisdição, da seguinte forma: $40 \%$ de votos para representantes dos usuários da água; $40 \%$ para população da bacia; e $20 \%$ para os órgãos Federais e Estaduais atuantes na região e que estejam relacionados com os recursos hídricos.

A instância superior à ARH é a FEPAM, mas este órgão é também muito importante na diversidade de processos de licenciamento no Estado. Esta entidade, é responsável por operacionalizar a outorga pelo uso da água para diluição de efluentes, determinação do enquadramento dos corpos d'água em classes de uso, como também a vazão ecológica [18]. Sobretudo, a FEPAM é especialmente voltada para regulamentar atividades potencialmente poluidoras ou utilizadoras de recursos naturais. Porém, é importante diferenciar que outorga para captação direta ou para armazenamento hídrico é atribuição do DRH/RS.

Nesse sentido, muito do apoio técnico aos $\mathrm{CBH}$ acaba vindo do $\mathrm{DRH}$, também decorrente de sua natureza no sistema. Este órgão tem competência de assistir tecnicamente e propor critérios para outorga ao $\mathrm{CRH}$; expedir as respectivas autorizações de uso da água; regulamentar a operação e uso dos equipamentos e mecanismos de gestão de recursos hídricos [17]. Reitera-se que o DRH tem atuado diretamente na elaboração de alguns planos de bacia no Estado.

O Estado do Rio Grande do Sul já finalizou o seu Plano Estadual de Recursos Hídricos (PERH/RS), instituído por meio da Resolução do $\mathrm{CRH} / \mathrm{RS}$ no 141 de 21 março de 2014. Importante destacar, que o referido Plano ainda se encontra em forma de minuta de lei na assembleia do estado, e que para ser válido é necessário que o mesmo seja aprovado por algum decreto ou lei.

O PERH/RS é o instrumento de planejamento estratégico da Política Estadual de Recursos Hídricos, que estabelece diretrizes gerais sobre o uso dos recursos hídricos no Estado, com intuito de promover a harmonização e adequação de políticas públicas na busca do equilíbrio entre a oferta e a demanda de água, por meio do uso racional, de forma a assegurar a disponibilidade hídrica em quantidade e qualidade, garantindo o uso sustentável [19].

\section{Instrumentos das Políticas de Recursos Hídricos}

No artigo $5^{\circ}$ da PNRH, são expostos os seus instrumentos, que também são os mesmos no SERH/RS os quais são os seguintes: I) os Planos de Recursos Hídricos; II) o enquadramento dos corpos de água em classes, segundo os usos preponderantes da água; III) a outorga dos direitos de uso de recursos hídricos; IV) a cobrança pelo uso de recursos hídricos; V) o Sistema de Informações sobre Recursos Hídricos. Os instrumentos de gestão visam alcançar diferentes fins, na maioria das vezes difusos e cíclicos. Nisso tem-se, por exemplo, o disciplinamento, incentivo, apoio a informação.

Dentre os instrumentos mencionados acima, o Plano de Bacia é o que permite integrar e articular os demais instrumentos da política de recursos hídricos, além de orientar as ações de gestão integrada e compartilhada dos usos multissetoriais dos recursos hídricos superficiais e subterrâneos [20]. A Figura 2 apresenta os instrumentos estabelecidos pela PNRH e a relação existente entre os mesmos, tendo o Plano de Recursos Hídricos como elemento integrador. 


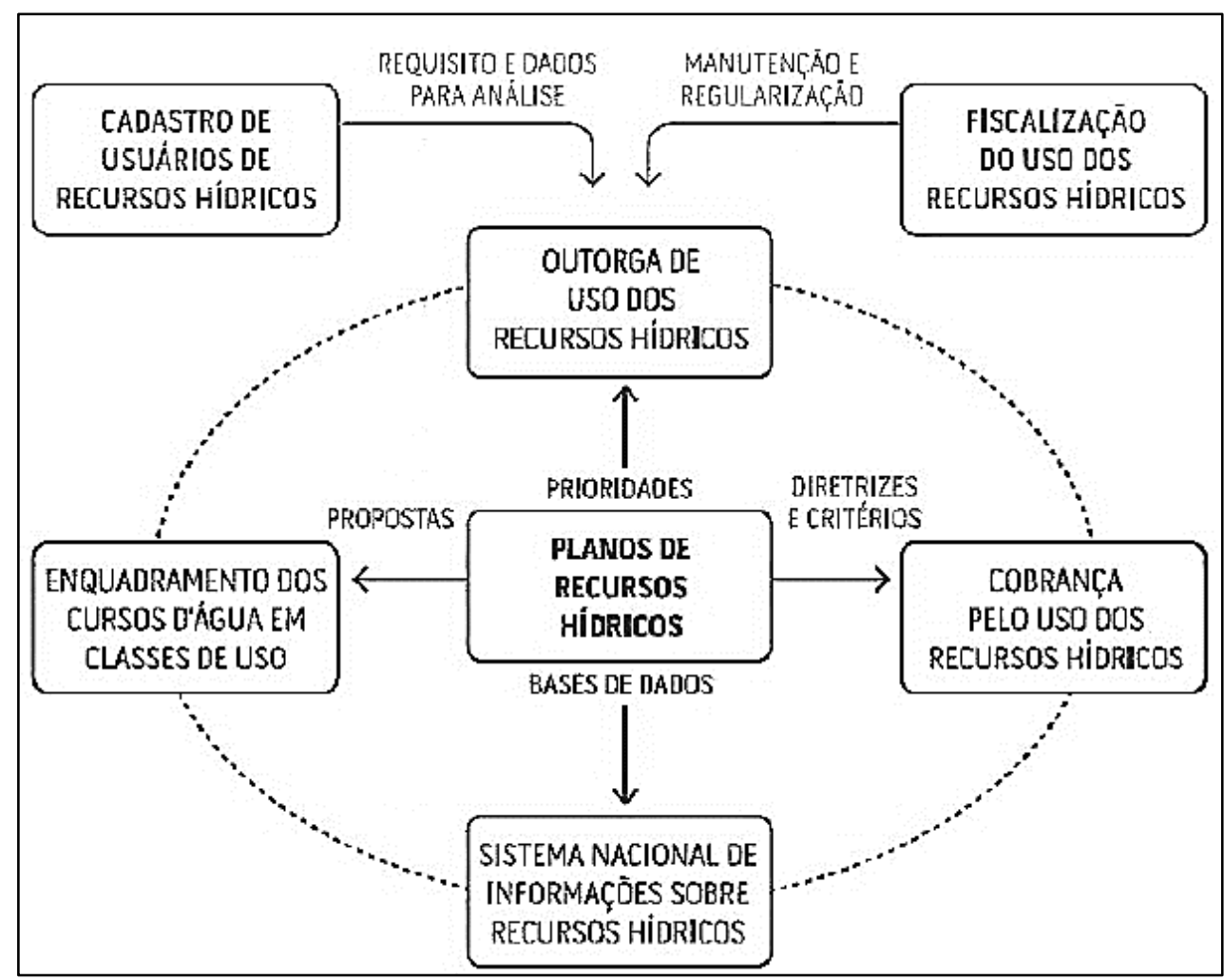

Figura 2. Relação entre os instrumentos da PNRH. Fonte: [21].

Os artigos $26^{\circ}, 27^{\circ}$ e $28^{\circ}$ da Lei Estadual $n^{\circ} 10.350$ de 1994 tratam especificamente dos planos de bacia hidrográfica. Segundo o artigo $26^{\circ}$, o PBH visa operacionalizar, no âmbito de cada bacia hidrográfica, por um período de 4 anos, com atualizações periódicas a cada 2 anos, as disposições do Plano Estadual de Recursos Hídricos, compatibilizando os aspectos quantitativos e qualitativos, de modo a assegurar que as metas e usos previstos pelo Plano Estadual de Recursos Hídricos sejam alcançados simultaneamente com melhorias sensíveis e contínuas dos aspectos qualitativos dos corpos de água.

No artigo $27^{\circ}$, tem-se os elementos constitutivos dos Planos de Bacia Hidrográfica: I) Objetivos de qualidade a serem alcançados em horizontes de planejamento não inferiores ao estabelecido no Plano Estadual de Recursos Hídricos; II) Programas das intervenções estruturais e não-estruturais e sua especialização; III) Esquemas de financiamento dos programas a que se refere o inciso anterior. Neste último, tais planeamentos podem ocorrer por determinação dos valores cobrados pelo uso da água; rateio dos investimentos de interesse comum; previsão dos recursos complementares alocados pelos orçamentos públicos e privados na bacia. Por fim, no artigo $28^{\circ}$, os $\mathrm{PBH}$ serão elaborados por Agências de Região Hidrográfica $(A R H)$, bem como aprovados pelos respectivos Comitês Bacia Hidrográfica $(\mathrm{CBH})$.

Os dois primeiros instrumentos indicados pela $\mathrm{PNRH}$, plano de recursos hídricos e enquadramento, visam construir consensos na bacia hidrográfica [22, 23]. Estes ampliam possibilidades de planejamento tradicional, abrindo espaços para inserção da sociedade civil, agentes econômicos com interesses particulares, na tentativa de construir consensos. O instrumento cobrança é o aditivo econômico para a gestão das águas. Estes são descentralizados e visam valorizar economicamente a água, segundo a sua escassez. Percebe-se que, pela dificuldade de aplicação da cobrança pelo uso da água, este instrumento é ainda amplamente considerado, pelos usuáriospagadores, um artifício meramente arrecadatório [24]. 
No Estado do Rio Grande do Sul, o sistema de planejamento do uso dos recursos hídricos (enquadramento, outorga, cobrança, etc), depois de aprovados pelo Conselho de Recursos Hídricos do Estado, as propostas ou critérios devem ser aprovados pelo $\mathrm{CNRH}$, para então, estas deliberações se tornarem leis.

\subsection{Planos de Recursos Hídricos}

Os planos de recursos hídricos são planos diretores com a finalidade de fundamentar e orientar a implementação da política de recursos hídricos e seu gerenciamento. Pode-se conceituar plano como sendo: "instrumentos de planejamento que servem para orientar a sociedade e, mais particularmente, a atuação dos gestores, no que diz respeito ao uso, recuperação, proteção, conservação e desenvolvimento dos recursos hídricos" [20].

Esses instrumentos destacam-se dentre os dispositivos de gestão das águas, como documentos em que os setores usuários podem reivindicar e negociar acerca de questões atuais e planos futuros de utilização da água. Este é o momento onde os usuários podem exercer sua influência no sistema por meio da representação e representatividade efetivadas através dos Comitês de bacia, para que com a ativa participação, haja um maior poder de negociação $[9,17]$.

\subsection{Enquadramento dos corpos de água em classes}

As classes ou padrões de qualidade dos corpos hídricos em vigência no Brasil são determinadas pela Resolução no 357 de 2005, do Conselho Nacional do Meio Ambiente (CONAMA). Esta define o enquadramento como sendo uma meta de qualidade (classe) a ser alcançada ou mantida em um segmento de corpo de água, conforme os usos preponderantes pretendidos, ao longo do tempo [25]. Atualmente, existem outras regulamentações em vigor acerca do enquadramento, a saber: Resolução CONAMA no 396/2008, que estabelece o enquadramento das águas subterrâneas; Resolução CNRH no 91/2008, que estabelece os procedimentos gerais para o enquadramento dos corpos d'água superficiais e subterrâneos; Resolução CNRH no 141/2012, que estabelece critérios e diretrizes para implementação dos instrumentos de outorga e de enquadramento em rios intermitentes e efêmeros.

No âmbito do Plano de bacia, o processo de elaboração da proposta de enquadramento deve ter ampla participação da comunidade da bacia, por meio da realização de consultas públicas, encontros técnicos e oficinas de trabalho, discutidas e pactuadas no Comitê de bacia [26].

Na prática, para estabelecer um objetivo de qualidade da água é preciso - avaliar a condição atual do rio, ou seja: "o rio que temos"; discutir com a população da bacia, a condição de qualidade desejada para aquele rio, "o rio que queremos"; e, por fim, discutir e pactuar a meta com os diferentes atores da bacia hidrográfica, "o rio que podemos ter", levando em conta as limitações técnicas e econômicas para o seu alcance [20].

Conforme a Resolução CONAMA no 357/2005, o Conselho Nacional e os Conselhos Estaduais de Recursos Hídricos devem determinar as normas e procedimentos do enquadramento. No Estado do RS, por exemplo, cabe aos Comitês de Bacia Hidrográfica propor ao órgão competente o enquadramento, sendo de competência das Agências de Região Hidrográfica subsidiar tecnicamente os Comitês [5]. 
De acordo com um levantamento realizado nas Resoluções do $\mathrm{CRH}$ no Estado do Rio Grande do Sul, no ano de 2016, existiam treze (aproximadamente 50\%) bacias de domínio Estadual com o instrumento enquadramento implantado [26].

Importante destacar a realização de alguns avanços na legislação desde o ano de 1999, tal como a ampliação do número de bacias com a implementação desse instrumento. No entanto, na prática ainda são observadas algumas dificuldades técnicas e operacionais para a sua aplicação [27, 28].

\subsection{Outorga dos direitos de uso de recursos hídricos}

A outorga é o ato administrativo no qual o poder público outorgante, podendo este ser a União, estado ou Distrito Federal, faculta ao outorgado (requerente) o direito de uso de recursos hídricos, por prazo determinado, nas condições expressas no respectivo ato [29].

No Brasil, a outorga é um instrumento indispensável para a gestão dos recursos hídricos, pois possibilita aos gestores, o controle quantitativo e qualitativo dos usos da água, ao mesmo tempo que garante o usuário o aproveitamento de água em local determinado do manancial hídrico, no qual a vazão, o tipo e o tempo de uso devem ser previamente definidos [30].

A outorga de direito de uso de recursos hídricos é indispensável para obtenção de licenciamento de diversas atividades junto aos órgãos ambientais, assim como para obtenção de financiamentos junto a instituições financeiras públicas e privadas [31].

A maioria dos conflitos pelo uso da água decorre da falta de planejamento dos recursos hídricos, a qual está intimamente ligada à inexistência de informações que associem as vazões já outorgadas com a disponibilidade hídrica". Assim, o conhecimento da distribuição espacial dos usos da água na bacia hidrográfica torna-se indispensável para a condução de uma adequada gestão de recursos hídricos. [32, 33].

No que tange aos critérios para análise dos pedidos de outorga, esses, utilizam diferentes vazões mínimas de referência, assim como percentuais considerados outorgáveis. A determinação desse percentual deve ser realizada em função da possibilidade de atendimento aos diversos usos da água na bacia e das vazões mínimas remanescentes que se deseja manter nos cursos de água. [20,33].

Como critério de outorga para águas superficiais, a União adota a vazão correspondente a $70 \%$ da $Q_{95}$, podendo essa vazão ser adaptada para cada Estado, e variar em função das peculiaridades de cada região. Para o Estado do RS, é utilizado o percentual máximo outorgável de $50 \%$ da Q90 definido no Plano Estadual de Recursos Hídricos (PERH/RS) [30]. Para as bacias hidrográficas do Estado que ainda não possuem seus planos de recursos hídricos, deve ser considerado o critério de outorga vigente estabelecido no $\mathrm{PERH} / \mathrm{RS}$, no entanto esses valores devem ser definidos no âmbito do comitê, no processo de elaboração do respectivo plano, considerando as peculiaridades da região.

Cabe aqui destacar, a importância de serem repassados os volumes de água utilizados pelos usuários, ao poder público outorgante (federal ou estadual), mesmo nos casos onde não existe a obrigatoriedade da outorga. Essas informações servem para compor o cadastro de usuários, a partir do qual, é possível conhecer a real demanda pelo uso da água, fundamental para a efetiva gestão e planejamento do uso dos recursos hídricos. 
$\mathrm{Na}$ esfera Federal, a ANA é responsável por manter um Cadastro Nacional de Usuários de Recursos Hídricos - CNARH (atualmente existe uma nova versão desse sistema, denominado Sistema Federal de Regulação de Uso - REGLA) contendo os registros dos usuários de recursos hídricos (superficiais e subterrâneos) que captam água, lançam efluentes ou realizam demais interferências diretas em corpos de água.

Da mesma forma, o Estado do Rio Grande do Sul tem avançado em um cadastro de usuários da água, denominado Sistema de Outorga de água - SIOUT/RS. O intuito é aperfeiçoar o gerenciamento das concessões inerentes às outorgas. O DRHS/RS é o responsável pela emissão das outorgas para os usos que alterem as condições quantitativas das águas.

\subsection{Cobrança pelo uso de recursos hídricos}

A PNRH, instituída pela "Lei das Águas", foi inspirada na experiência francesa de gestão e tem a Cobrança pelo uso das águas dentre suas maiores inovações institucionais. A cobrança pelo uso de recursos hídricos não é considerada um imposto, mas um preço público, onde seus mecanismos e valores são negociados por meio de debates públicos no âmbito dos Comitês de Bacia Hidrográfica [13]. Para que a implementação da cobrança tenha sucesso, é fundamental que haja integração com os demais instrumentos de gestão das águas, principalmente com a outorga de direito de uso, uma vez que a Lei no 9.433/97 estabelece que os usos de recursos hídricos a serem cobrados são aqueles sujeitos à outorga.

É por meio da cobrança pelo uso da água que se materializa o reconhecimento da água como um bem econômico e dotado de um valor de uso e de troca. Esse instrumento atua como um elemento indutor da gestão participativa, descentralizada e integrada por todos interessados, uma vez que estão entre as atribuições dos integrantes do comitê de bacia, a discussão dos níveis de preço, o modo de implementação e as necessárias alterações de rumo, quando a cobrança estiver sendo aplicada [34].

A Lei das Águas estabelece, em seu artigo 19, que a cobrança pelo uso da água tem como objetivos: reconhecer a água como bem econômico; incentivar a racionalização do seu uso; e obter recursos para o financiamento dos programas e intervenções contemplados nos planos de recursos hídricos. Essas finalidades foram fortalecidas com a instituição da Resolução no 48/2005 do CNRH, posto que, estabeleceu critérios mais abrangentes para a cobrança pelo uso dos recursos hídricos, uma vez que a Lei 9.433/97 determina critérios gerais para os valores a serem cobrados nas derivações, captações e extrações de água e para lançamento de esgotos e demais resíduos.

No tocante aos valores arrecadados com a cobrança pelo uso de recursos hídricos, a Lei $n^{\circ}$ 9.433/97 determina que serão aplicados prioritariamente na bacia hidrográfica em que foram gerados e serão utilizados tanto nos programas de ações e projetos incluídos nos Planos de Recursos Hídricos, como para o pagamento de despesas de implantação e custeio administrativo dos órgãos e entidades integrantes do SINGREH, contudo, a aplicação dessas despesas é limitada a 7,5\% (sete e meio por cento) do total arrecadado [4].

No Estado do Rio Grande do Sul, a Lei no 10.350/94, estabelece que os recursos provenientes da cobrança pelo uso da água serão destinados a aplicações exclusivas e não transferíveis na gestão dos recursos hídricos da bacia hidrográfica de origem, corroborando com a legislação Federal, e esclarecendo com mais detalhes, conforme descrito no seu artigo 32: I - A cobrança de valores está vinculada à existência de 
intervenções estruturais e não estruturais aprovadas para a respectiva bacia, sendo vedada a formação de fundos sem que sua aplicação esteja assegurada e destinada no Plano de Bacia Hidrográfica; II - até $8 \%$ (oito por cento) dos recursos arrecadados em cada bacia poderão ser destinados ao custeio dos respectivos Comitê e Agência de Região Hidrográfica; III - até $2 \%$ (dois por cento) dos recursos arrecadados em cada bacia poderão ser destinados ao custeio das atividades de monitoramento e fiscalização do órgão ambiental do Estado desenvolvidas na respectiva bacia [5].

Atualmente, no cenário nacional, a cobrança pelo uso de recursos hídricos já se faz presente em seis bacias hidrográficas de rios de domínio da União, quais sejam: Bacia do Rio Paraíba do Sul, Bacias dos Rios Piracicaba, Capivari e Jundiaí, Bacia do Rio São Francisco, Bacia do Rio Doce, Bacia do Rio Paranaíba e Bacia do Rio Verde Grande. Na esfera dos Estados, embora a cobrança esteja prevista em todas políticas, poucos possuem esse instrumento em operação [35].

A primeira experiência estadual de implantação da cobrança pelo uso de recursos hídricos, ocorreu no Estado do Ceará. Além deste, em rios de domínio dos Estados do Rio de Janeiro, São Paulo, Minas Gerais, Paraná e Paraíba esse instrumento também já se encontra em execução [35].

Embora a cobrança pelo uso da água ainda não tenha sido implementada no Rio Grande do Sul, o Estado vem avançando para a efetiva gestão e racionalização dos usos da água. Um exemplo disso é o que vem ocorrendo na Bacia Hidrográfica do Rio Gravataí, onde no final do ano de 2018, o Comitê da Bacia encaminhou as últimas medidas para implementação da cobrança pelo uso de suas águas.

A referida bacia, será cenário de um projeto-piloto para efetivação desse instrumento no Estado, que já possui a cobrança aprovada na legislação há mais de 24 anos e até os dias atuais não a efetivou. Assim, será o primeiro modelo de cobrança implementado no Estado [36]. Paralelo a esse projeto, o DRHS enviou propostas de valores ao $\mathrm{CRH} / \mathrm{RS}$, nesse caso, o objetivo é que se venha a estabelecer valores referenciais mínimos para todo o Estado. A discussão, por enquanto, não tem ligação com o Rio Gravataí, que é o projeto-piloto, mas tem o objetivo de encaminhar a questão da cobrança pelo uso da água no restante das bacias hidrográficas gaúchas [36].

\subsection{Sistema de informações sobre recursos hídricos}

Os sistemas de informações sobre recursos hídricos são instrumentos de disponibilização de dados e acesso informacional pela população geral, democraticamente [37]. Trata-se de um mecanismo para difundir gratuitamente 0 conhecimento em todo o Brasil sobre os recursos hídricos. Em nível federal, tem-se o Sistema Nacional de Informações sobre Recursos Hídricos (SNIRH), que foi implementado e é operacionalizado pela ANA. Este sistema reúne diversas informações temáticas e é composto por subsistemas que permitem visualizar e realizar download de dados para fins de processamentos, cruzamentos e demais manipulações com vistas a realização de análises [9]. Dentre os principais materiais e ferramentas atualmente disponibilizadas pelo SNIRH, tem-se as seguintes: a) Relatório de conjuntura dos Recursos Hídricos; b) Mapas interativos; c) Painel de indicadores; d) Descarregamento de metadados geoespaciais; e) Acesso a subsistemas, como Sistema de Informações Hidrológicas (Hidroweb), Sistema de Acompanhamento de Reservatórios (SAR), Sistema Federal de Regulação de Usos (REGLA); f) Monitoramento de recursos hídricos por aplicativo; g) Portal de dados abertos. 
Já no RS, o Sistema Estadual de Informações sobre os Recursos Hídricos (SEIRH) não é considerado um instrumento, mas uma condição estratégica para efetivar os demais instrumentos do SERH [38]. O SEIRH é considerado instrumento apenas na $\mathrm{PNRH}$, mas que sem tal ferramenta no âmbito do $\mathrm{SERH}$, não funcionaria nada da gestão das águas, devido a falta de informações ordenadas sobre recursos hídricos. Assim, em nível estadual, os órgãos gestores tem mantido seus sistemas de informação, porém geralmente em níveis menores de quantidade e qualidade das informações em comparação com o SNIRH/ANA. Reitera-se que a divulgação de informações deve ajudar a consolidar um processo de construção de um olhar crítico sobre a realidade ambiental das águas das bacias hidrográfica, mas também de seus aspectos sociais, econômicos e culturais [6].

\section{Desafios e entraves do SERH em relação à PNRH}

Apesar do SERH/RS ter se antecipado três anos quanto a promulgação do $\mathrm{PNRH}$, o sistema tem encontrado dificuldades em avançar no preconizado em sua estrutura, mesmo sendo muito semelhante a lei nacional. O principal desafio do SERH se encontra na dificuldade de suas entidades se colocarem no caminho do crescimento socioeconômico, no sentido de mostrar sua importância para tais setores, com interesses diferenciados sobre recursos hídricos [6]. Estes não conseguem compreender a importância que a gestão das águas representa para eles mesmos e para o funcionamento da sociedade e da necessidade eminente de se promover a preservação do meio natural [39]. Tal complexidade se reflete na dificuldade do Estado em promover, implementar e consolidar o enquadramento e cobrança pelo uso da água, bem como instaurar as Agências de Região Hidrográfica e administrar conflitos dos usos múltiplos. Não obstante, o reflexo se estende para a morosa execução, no território das bacias hidrográficas, das ações propostas nos PBHs. Após 26 anos da promulgação da Lei n 10.350 de 1994, das 25 bacias hidrográficas no Estado do Rio Grande do Sul, somente 8 possuem $\mathrm{PBH}$ em fase $\mathrm{C}$, isto é, apenas $32 \%$ atingiram o estágio de formulação de programas e ações [38]. Diante do exposto, a seguir, serão apresentadas considerações que explicam esses entraves.

\subsection{O precário suporte aos Comitês de Bacia Hidrográfica do RS}

No Art. $12^{\circ}$, da Lei $n^{\circ} 10.350$ de 1994 , os CBH's ficaram incumbidos da coordenação programática das atividades dos agentes públicos e privados, relativos a água, compatibilizando na sua respectiva bacia hidrográfica, metas do $\mathrm{PERH}$ com a crescente melhoria da qualidade dos corpos de água. No Art. $4^{\circ}$, a segunda diretriz é nítida ao expressar o compromisso de apoio técnico por parte do Estado para as ARH's, que contribuiriam tecnicamente nas vias econômica e ambiental para os CBH's de cada região. Assim, compilando os demais princípios legais, o sistema de funcionamento dos comitês está baseado no tripé descentralização, participação e integração, cuja ênfase é quanto a qualidade e quantidade das águas, via ações promotoras de usos múltiplos na bacia hidrográfica. Este é um processo ainda em consolidação, estando a prioridade dos organismos de bacia centrada na criação dos instrumentos necessários para a gestão [40].

A criação dos instrumentos, que os autores acima se reportam, tem estado dependente de outras entidades, pois os $\mathrm{CBH}$ não possuem o suporte de uma $\mathrm{ARH}$, que seria atribuição do Estado criar. Isso tem gerado e mantido uma dicotomia entre gestão e execução de instrumentos por parte dos CBH's. A larga competência incumbida aos CBH's, expressa no Art. $12^{\circ}$ do $\mathrm{SERH}$, somados a uma holística participação social, torna branda a atuação a capacidade técnica para aprofundar-se em seus instrumentos, na medida em que os problemas a serem atacados tornam-se 
mais complexos. O problema, nesse caso, recaí na capacitação de membros do CBH's.

O não cumprimento da diretriz de criação de ARH's pelo Estado, tem sido parcialmente suprido pelo Programa Nacional de Fortalecimento dos Comitês de Bacias Hidrográficas - Procomitês, instituído pela Resolução ANA no 1.190 de 2016, criado para promover o aprimoramento dos comitês de bacia hidrográfica dos estados e do Distrito Federal [21]. O programa integra iniciativas os programas Progestão e o Qualiágua, que apoia financeiramente entidades constituintes do SINGREH, desde que se cumpra metas pactuadas e contratadas, consentidas pelos $\mathrm{CERH}$.

Apesar de ser um programa recente, amplamente difundido e benéfico financeiramente aos CBH's, este não consegue ser um denominador comum entre gestão e execução, principalmente quanto ao apoio técnico, essencial aos Comitês. Isso se percebe pelos mecanismos diminuidores dessa lacuna, em alguns CBH's do RS, como convênios e concessões técnicas com entidades não pertencentes ao SINGREH e SERH, como universidades, institutos de tecnologia e empresas privadas. São tentativas, de diferentes formas e escalas, de obter o suporte técnico que falta, mas que é previsto em lei. Seria este que cumpriria a compatibilização das metas do $\mathrm{PERH}$, com a incumbência do $\mathrm{CBH}$ em coordenar atividades públicas e privadas na bacia hidrográfica. Logo, a maioria do CBH's não encontra um suporte local para dirimir demandas técnicas de sua bacia, por meio de projetos e outras formas de trabalho.

\subsection{Falta de sinergia dos órgãos do SERH acerca dos instrumentos}

Para existir uma sinergia do SERH ao desenvolvimento socioeconômico, há a necessidade de implementação dos sistemas de informações, vinda de vários órgãos ligados ao SERH (DRH, CRH, SEMA, FEPAM, CBH etc.), porque falta uma base de dados e um instrumento que pudesse agilizar e automatizar as decisões referentes as águas [41]. A estrutura geral destes sistemas de informações sobre recursos hídricos é composta de subsistemas integrados e interdependes: Regulação de Uso; Planejamento e Gestão; Quali-quantitativo; inteligências hídricas; inteligência documental e inteligência geográfica. Esta estrutura geral criada pela ANA (responsável por implementar o SNIRH) contempla as características que a legislação de recursos hídricos nacional determina para a constituição do SNIRH [8].

Observa-se a amplitude estrutural do $\mathrm{SNIRH}$, que foi replicada ao $\mathrm{SERH}$ para uso, chamado Sistema Estadual de Informações de Recursos Hídricos (SEIRH). No RS, este não é um instrumento, mas sim uma condição estratégica para efetivar os mesmos [39], via base de dados consistente e atualizada, com acesso as informações de cada bacia hidrográfica. Claramente, para atender cada parte dessa estrutura e prover precisas informações para aplicação de todos os instrumentos promulgados em lei, os órgãos gestores devem possuir um corpo técnico especializado. Não obstante, na medida em que o SEIRH ainda não foi implantado integralmente, vem sendo atualmente responsabilidade do $\mathrm{DRH}$ sua efetivação, decorrente da natureza da entidade no sistema, bem como porque este órgão tem atuado diretamente na elaboração de alguns planos de bacia do SERH. As ARH seriam responsáveis pelo gerenciamento do $\mathrm{SEIRH}$, mas, não estando criadas ainda, a responsabilidade fica a cargo do $\mathrm{DRH}[8]$.

Diante do exposto, na medida em que carece a criação da $A R H$, no contexto descentralizado em que se insere a Política de Recursos Hídricos, a implementação de $\mathrm{PBH}$ e SEIRH pode ser potencializada pela participação efetiva dos $\mathrm{CBH}$ no acompanhamento do mesmo. Nota-se que os $\mathrm{CBH}$, integrante do $\mathrm{SERH}$, não 
conseguem atuar ativamente na análise ou tomada decisão para isso. Ao passo que os outros órgãos pertencentes ao $\mathrm{SERH}$, atualmente, possuem várias funções executivas (monitoramento de chuvas, cheias, manutenção de viveiros de espécies nativas, etc.), o CBH consegue expressar melhor a realidade local de gestão e dados. Por outro lado, os Comitês necessitam de capacidade de articulação política para manter as demandas do Plano na agenda do governo, dos setores usuários e da comunidade [11].

\subsection{Diferenças na celeridade de implantação dos instrumentos}

Os instrumentos de gestão de recursos hídricos apresentam uma forte dependência entre si e apresentam-se em diferentes estágios de implementação nas bacias hidrográficas brasileiras. No RS, dos diversos instrumentos existentes, o PERH é o documento norteador para todos, nas distintas escalas. Observa-se que a construção do PERH levou 7 anos para estar oficialmente concluída, cuja fase inicial foi em 2007 e a Resolução CRH n ${ }^{\circ} 141$ somente foi sancionada em 2014. Durante este processo, o estado natural de planejamento, corriqueiro nas bacias de dentro do Estado do RS, visou acompanhar o prescrito na Lei que originou o $\mathrm{PERH}$.

O referido processo de planejamento é usualmente arquitetado e compilado no $\mathrm{PBH}$, dividido em fases A, B e C. A fase A situa, via diagnóstico e prognóstico, a qualidade, quantidade, usos e demandas da água. Complementa-se essa fase com as seguintes informações: I) Localização, divisão política e hidrográfica da bacia; II) Questões históricas e socioculturais, evolução político administrativa e demografia; III) Indicadores econômicos; IV) Balanço hídrico da bacia. A fase B consiste em compatibilizar e articular os usos múltiplos da água. Usa-se o enquadramento dos cursos d'água como mecanismo para tanto, com metas, prazos e propostas genéricas para alcançar a qualidade preconizadas nos corpos hídricos. Por fim, na fase $\mathrm{C}$ tem-se a formulação de programas e ações, isto é, uma lista de atividades descritas, contendo estimativa de custos e definição de cronograma de implantação [22].

Porém, ao longo do tempo, dificuldades grandes ocorreram na elaboração das fases $B$ e C. Isto é, diversos planos não dissertaram, ou discorreram muito precariamente, por exemplo, acerca dos tópicos do item III do artigo $27^{\circ}$, da Lei 10.350 de 1994 , essencial para a aplicabilidade do PBH. Pela precariedade do foco nos referidos itens da Lei, tornou-se difícil visualizar os cenários para bacia. Os cenários, que poderiam representar nítidos horizontes de ação, tornam-se somente pautas, debatidos de modo disperso em reuniões ordinárias dos $\mathrm{CBH}$. Ainda, algumas ações previstas no Plano dependem de entes públicos e mesmo da discussão e aprovação de leis, tais como a cobrança do uso da água e compensação por serviços ambientais [42]. Nesse sentido, a discrepância temporal entre a existência de diversos $\mathrm{CBH}$ e a demora de finalização do $\mathrm{PERH}$, gerou a inércia quanto ao andamento de muitos instrumentos por anos. Isso reforça a ideia de que a gestão territorial local de cada bacia, pelos CBH's, deve seguir apenas diretrizes do $\mathrm{SERH}$, mas não a obediência e espera por regulamentos, pois isso engessa sua intensidade de atuação autônoma.

\section{Considerações Finais}

Embora a regulação dos recursos hídricos pareça ter os componentes necessários a plena articulação das águas, no RS, está existindo uma lacuna entre gestão e execução. Uma vez que existe amplitude na forma de expressão dos instrumentos de gestão das Leis $n^{\circ} 9.433$ de 1997 e 10.350 de 1994, percebe-se que a prioridade aumentar a implantação do SERH é buscar saber como viabilizar a articulação da gestão territorial. Ainda que o conteúdo dos instrumentos seja distinto por bacia 
hidrográfica, decorrente de suas peculiaridades, estes necessitam de agentes alocados nessas bacias, que rapidamente identifiquem as demandas de gestão.

Se, por um lado, os órgãos estaduais do $\mathrm{SERH}$, hoje, ainda possuem várias funções executivas em andamento, por outro são os $\mathrm{CBH}$ que possuem melhor expressão da realidade de suas bacias e territórios, bem como ações necessárias. Parece, sobretudo, ser preciso corrigir o balanço territorial de tais atividades entre as entidades, para assim ampliar e consolidar a descentralização da gestão das águas no Rio Grande do Sul. Do contrário, permanecerão indefinições quanto ao papel de cada entidade do SERH como implementador das políticas de recursos hídricos.

\section{Referências}

[1] Hartmann P. A cobrança pelo uso da água como instrumento econômico na política ambiental. Porto Alegre: AEBA, 2010. 532p. Disponível em: $<$ https://www.kas.de/c/document_library/get_file?uuid=6b4bf606-1489-efda-c02307c329797aac\&groupld=252038>. Acesso em: 16 jan. 2021.

[2] Thomas P.T. Proposta de uma metodologia de cobrança pelo uso da água vinculada à escassez. Tese de Doutorado. Rio de Janeiro: Universidade Federal do Rio de Janeiro; 2002.

[3] Brasil. Constituição da República Federativa do Brasil: promulgada em 5 de outubro de 1988. Brasília, DF. Disponível em: <http://www.planalto.gov.br/ccivil_03/Constituicao/Constituicao.htm>. Acesso em: 15 dez. 2020.

[4] Brasil. Lei Federal $n^{\circ}$ 9.433, de 08 de janeiro de 1997. Institui a Política Nacional de Recursos Hídricos, cria o Sistema Nacional de Gerenciamento de Recursos Hídricos, regulamenta o inciso XIX do art. 21 da Constituição Federal. Diário Oficial da União, Brasília, DF, 9 jan. $1997 . \quad$ Disponível em: <http://www.planalto.gov.br/ccivil_03/LEIS/L9433.htm>. Acesso em: 23 nov. 2020.

[5] Rio Grande do Sul. Lei no 10.350, de 30 de dezembro de 1994. Institui o Sistema Estadual de Recursos Hídricos. Disponível em: <http://www.al.rs.gov.br/filerepository/repLegis/arquivos/10.350.pdf >. Acesso em: 23 nov. 2018.

[6] Meier M.A. A conjuntura dos instrumentos da política estadual de recursos hídricos no estado do Rio Grande do Sul. Dissertação de Mestrado. Porto Alegre. Universidade Federal do Rio Grande do Sul; 2011.

[7] Bernardi E.W., Panziera A.G., Buriol A.G., Swarowsky A. Bacia hidrográfica como unidade de gestão ambiental. Revista Disciplinarum Scientia 2012; 13(2):158-168. https://doi.org/10.37779/nt.v13i2.1303.

[8] Peres B.R., Silva S. Análise das relações entre o plano de bacia hidrográfica TietêJacaré e os planos diretores municipais de Araraquara, Bauru e São Carlos, SP: avanços e desafios visando a integração de instrumentos de gestão. Sociedade \& Natureza 2013; 25(2):349-362. https://doi.org/10.1590/S1982-45132013000200011.

[9] Tamiosso C.F., Dulac V.F., Swarowsky, A. Política Nacional de Recursos Hídricos: uma revisão dos instrumentos de gestão das águas no Brasil. XXII Simpósio Brasileiro de Recursos Hídricos. Florianópolis, SC. 2017. Disponível em: <https://s3-sa-east- 
1.amazonaws.com/abrh/Eventos/Trabalhos/60/PAP022914.pdf>. Acesso em: 16 jan. 2021.

[10] Secretaria Estadual do Ambiente e Desenvolvimento Sustentável - SEMA. Serviços e informações. Recursos Hídricos. 2018. Disponível em: <https://www.sema.rs.gov.br/recursos-hidricos>. Acesso em: 15 dez. 2020.

[11] Agência Nacional de Águas - ANA. O que é SINGREH. Disponível em: <https://www.ana.gov.br/aguas-no-brasil/sistema-de-gerenciamento-de-recursoshidricos/o-que-e-o-singreh>. Acesso em: 16 dez. 2020.

[12] Libânio P.A.C. O uso de estratégias focadas em resultados para cooperação transversal e federativa no SINGREH. In: Congresso Brasileiro de Águas Subterrâneas (CBAS'14); 2014; São Paulo. São Paulo: ABAS; 2014. p. 1-20.

[13] Agência Nacional de Águas - ANA. Agência de Água: O que é, o que faz e como funciona. Cadernos de Capacitação em Recursos Hídricos. v. 4. Brasília: ANA, 2014. Disponível em: <https://arquivos.ana.gov.br/institucional/sge/CEDOC/Catalogo/2014/CadernosdeCapa citacaoemRecursosHidricosVol4.pdf>. Acesso em: 16 jan. 2021.

[14] Rio Grande do Sul. Decreto $n^{\circ}$ 53.885, de 16 de janeiro de 2018. Institui subdivisão das Regiões Hidrográficas do Estado do Rio Grande do Sul em Bacias Hidrográficas. Diário Oficial do Estado, Porto Alegre, RS, 17 jan. 2018. Disponível em: <https://www.sema.rs.gov.br/upload/arquivos/201803/08095109-decreto-53885-

2017.pdf>. Acesso em: 10 nov. 2020.

[15] Rio Grande do Sul. Plano Estadual de Recursos Hídricos do Estado do Rio Grande do Sul: Relatório Síntese da Fase A. Porto Alegre: ECOPLAN, 2007. 146 p.

[16] Departamento de Recursos Hídricos do Estado do Rio Grande do Sul - DRH/RS. www.sema.rs.gov.br/.../DRH_Oficina_ANA_2011.ppt. Acesso em: 11 nov. 2020.

[17] Dulac V.F. Análise dos instrumentos de gestão dos recursos hídricos com ênfase nas ações do comitê de bacia hidrográfica do Rio Santa Maria, RS. Dissertação de Mestrado. Santa Maria. Universidade Federal de Santa Maria; 2013.

[18] Dulac V.F., Cruz, R.C. Mapeamento das Ações de Gestão dos Recursos Hídricos no Âmbito de um Comitê de Gerenciamento de Bacia Hidrográfica. Revista Brasileira de Recursos Hídricos; (20)3: p. 583-593, 2015. Disponível em: <https://abrh.s3.saeast-

1.amazonaws.com/Sumarios/182/c81ecc15299816d6de96ee20ecb8e74d_69e907108 b130c37ade36884996a6ab6.pdf>. Acesso em: 16 jan. 2021.

[19] Conselho de Recursos Hídricos do Rio Grande Sul CRH/RS. Resolução no 141, de 21 de março de 2014 do Conselho de Recursos Hídricos do Rio Grande do Sul. Institui o Plano Estadual de Recursos Hídricos do Estado do Rio Grande do Sul $\mathrm{PERH} / \mathrm{RS}$. Disponível em: <https://www.sema.rs.gov.br/upload/arquivos/201708/22164454-resolucao-crh-1412014-institui-plano-estadual-recursos-hidricos-estado-rs-28-03.pdf>. Acesso em: 15 dez. 2020.

[20] Agência Nacional de Águas - ANA. Planos de Recursos Hídricos e Enquadramento dos corpos de Água. Brasília, DF. Cadernos de Capacitação em Recursos Hídricos. v. 5. Brasília, v. 5, 2013. Disponível em: 
<https://arquivos.ana.gov.br/institucional/sge/CEDOC/Catalogo/2013/planoDeRecurso sHidricosEnquadramento.pdf>. Acesso em: 16 jan. 2021.

[21] Agência Nacional de Águas - ANA. Conjuntura dos Recursos Hídricos no Brasil. Brasília: $\quad$ ANA; $2017 . \quad 169 \quad$ p. Disponível em: <http://www.snirh.gov.br/portal/snirh/centrais-de-conteudos/conjuntura-dos-recursoshidricos/relatorio-conjuntura-2017.pdf/view>. Acesso em: 16 jan. 2021.

[22] Porto M.F.A., Lobato F. Mechanisms of Water Management: Command \& Control and Social Mechanisms (Parte 1 de 2). Revista de Gestão da Água da América Latina 2004; 1:113-129. Disponível em: <https://www.abrhidro.org.br/SGCv3/publicacao.php?PUB=2\&ID=64\&SUMARIO=805> . Acesso em: 16 jan. 2021.

[23] Porto M.F.A., Lobato F. Mechanisms of Water Management: Economics Instruments and Voluntary Adherence Mechanisms (Parte 2 de 2). Revista de Gestão da Água da América Latina 2004; 1:132-146. Disponível em: <https://www.cepal.org/samtac/noticias/documentosdetrabajo/4/23394/inbr01705.pdf>. Acesso em: 16 jan. 2021.

[24] Porto M.F.A., Porto R.L.L. Gestão de bacias hidrográficas. Estudos Avançados; (22)63: p. 43-60, 2008. https://doi.org/10.1590/S0103-40142008000200004.

[25] Conselho Nacional de Meio Ambiente - CONAMA. Resolução no 357, de 17 de março de 2005 do Conselho Nacional do Meio Ambiente. Dispõe sobre a classificação dos corpos de água e diretrizes ambientais para o seu enquadramento. Disponível em: http://www2.mma.gov.br/port/conama/legiabre.cfm?codlegi=459. Acesso em: dez. 2020.

[26] Dulac V.F. et al. Enquadramento dos corpos de água na Bacia do Rio dos Sinos: aspectos metodológicos e estudo de caso. XX Simpósio Internacional de Qualidade Ambiental (SIQA '16); 19-21 outubro 2016; Porto Alegre. Rio Grande do Sul. 2016. p.

[27] Brites A.P.Z. Enquadramento dos corpos de água através de metas progressivas: probabilidade de ocorrência e custos de despoluição hídrica. Tese Doutorado. São Paulo: Universidade de São Paulo; 2010.

[28] Torres C., Medeiros Y.D., Freitas I.M.D.P. Training watershed committee members to aid on the decision-making process for the execution program of the framework of water bodies. Revista Brasileira de Recursos Hídricos 2016; (21)2:314-327. https://doi.org/10.21168/rbrh.v21n2.p314-327.

[29] Agência Nacional de Águas - ANA. Outorga de Direito de Uso de Recursos Hídricos. Cadernos de Capacitação em Recursos Hídricos. Volume 6. Brasília, 2011 54p. Disponível em: <https://arquivos.ana.gov.br/institucional/sge/CEDOC/Catalogo/2012/OutorgaDeDireito DeUsoDeRecursosHidricos.pdf>. Acesso em: 16 jan. 2021.

[30] Arai F.K. Critérios para concessão de outorga e eficiência do uso dos recursos hídricos pela irrigação. Tese Doutorado. Mato Grosso do Sul: Universidade Federal da Grande Dourados; 2014.

[31] Schvartzman A.S., Nascimento N.O., Von Sperling M. Outorga e cobrança pelo uso de recursos hídricos: aplicação à Bacia do rio Paraopeba, MG. RBRH - Revista 
Brasileira de Recursos Hídricos 2002; 7(1):103-122. https://doi.org/10.21168/rbrh.v7n1.p103-122.

[32] Moreira M.C., Silva D., Nunes A., Lara M. Índices para identificação de conflitos pelo uso da água: proposição metodológica e estudo de caso. Revista Brasileira de Recursos Hídricos 2012; 17(3):7-15. https://doi.org/10.21168/rbrh.v17n3.p7-15.

[33] Silva B.M.B., Silva D.D., Moreira M.C. Índices para a gestão e planejamento de recursos hídricos na bacia do rio Paraopeba, Estado de Minas Gerais. Revista Ambiente \& Água 2015; (10)3:685-697. http://dx.doi.org/10.4136/ambi-agua.1597.

[34] Carrera-Fernandez J., Garrido R.J. Economia dos Recursos Hídricos. Salvador: Edufba, 2002. 458 p.

[35] Agência Nacional de Águas - ANA. Cobrança. Histórico da Cobrança. Brasília, 2018. Disponível em: <http://www3.ana.gov.br/portal/ANA/gestao-daagua/cobranca/historico-da-cobranca>. Acesso em: 15 dez. 2020.

[36] Correio do Povo. Disponível em:

<http://www.correiodopovo.com.br/Noticias/Geral/Meio\%20Ambiente/2018/12/669239/ Rio-Gravatai-servira-como-projetopiloto-de-cobranca-pela-captacao-de-agua-no-RS>.

Acesso em: 01 dez. 2020.

[37] Martins J.V.R. O acesso à informação ambiental e a gestão hídrica: uma análise da implementação do Sistema Nacional de Informações sobre Recursos Hídricos (SNIRH). Revista Eletrônica de Ciência Política 2017; (8)3:33-57. http://dx.doi.org/10.5380/recp.v8i3.57153.

[38] Rio Grande do Sul. Estado da arte dos comitês em relação aos planos de bacia hidrográfica. Frederico Westphalen, RS, 2019. 1 mapa, color., 59,4x84,1 cm. Escala: 1:2.505.000. Disponível em: <www.sema.rs.gov.br/bacias-hidrograficas>. Acesso em: 14 dez. 2020.

[39] Paim P. Paulo Paim: Entrevista [julh. 2010]. Entrevistador: M. A. Meier. Porto Alegre: DRH-RS, 2010. $1 \mathrm{~cd}$ sonoro. Entrevista concedida ao projeto "A conjuntura dos instrumentos de gestão da Legislação dos Recursos Hídricos no Estado do Rio Grande do Sul".

[40] Jacobi P.R., Barbi F. Democracia e participação na gestão dos recursos hídricos no Brasil. Revista Katálysis. Florianópolis 2007; (10)2:237-244. https://doi.org/10.1590/S1414-49802007000200012.

[41] Silva J.M.T. João Manuel Trindade da Silva: Entrevista [abr. 2011]. Entrevistador: M. A. Meier. Porto Alegre: DRH-RS, 2011. $1 \mathrm{~cd}$ sonoro. Entrevista concedida ao projeto "A conjuntura dos instrumentos de gestão da Legislação dos Recursos Hídricos no Estado do Rio Grande do Sul".

[42] Cardoso P.L. Avaliação do plano de bacia hidrográfica do rio dos Sinos. 2019. 126 p. Dissertação de Mestrado. Canoas. Universidade La Salle; 2019.

\section{Autores}

André Panziera ${ }^{1}$, Camila Tamiosso ${ }^{1}$, Alexandre Swarowsky ${ }^{2, *}$ 
1. Programa de Pós-Graduação em Engenharia Agrícola, Universidade Federal de Santa Maria, Santa Maria - RS, Brasil.

2. Departamento de Engenharia Sanitária e Ambiental, Universidade Federal de Santa Maria, Santa Maria - RS, Brasil.

*Autor para correspondência: alexandre.swarowsky@ufsm.br 